\title{
Modifiable risk factors remain significant causes of medium term mortality after first time Coronary artery bypass grafting Babu Kunadian ${ }^{1}$, Joel Dunning ${ }^{1}$ and Russell WJ Millner*2
}

\author{
Address: ${ }^{1}$ Department of Cardiothoracic Surgery, The James Cook University Hospital, UK and ${ }^{2}$ Department of Cardiothoracic Surgery, Blackpool \\ Victoria Hospital, UK \\ Email: Babu Kunadian - Babu.Kunadian@stees.nhs.uk; Joel Dunning - joeldunning@doctors.org.uk; \\ Russell WJ Millner* - RussellMillner@aol.com \\ * Corresponding author
}

Published: 3 December 2007

Journal of Cardiothoracic Surgery 2007, 2:5 I doi:10.1 I86/1749-8090-2-5I
Received: 13 October 2007

Accepted: 3 December 2007

This article is available from: http://www.cardiothoracicsurgery.org/content/2/1/5 I

(c) 2007 Kunadian et al; licensee BioMed Central Ltd.

This is an Open Access article distributed under the terms of the Creative Commons Attribution License (http://creativecommons.org/licenses/by/2.0), which permits unrestricted use, distribution, and reproduction in any medium, provided the original work is properly cited.

\begin{abstract}
Background: Whilst there is much current data on early outcomes after Coronary artery bypass grafting(CABG), there is relatively little data on medium term outcomes in the current era. The purpose of this study is to present a single surgeon series comprising of all first time CABG patients operated on with the technique of cross clamp fibrillation from Feb-1996 to through to Jan-2003, and to seek risk factors for medium term mortality in these patients.

Methods: Data was collected from Hospital Episode Statistics and departmental patient administration and tracking systems and cross checked using database techniques. Patient outcomes were searched using the National Health Service strategic tracing service.

Results: Mean follow up was 5.3 years(0-9.4 years) and was complete for all patients. 30-day survival was $98.4 \%$, I-year survival $95 \%$ and 8 -year survival $79 \%$. Cox-regression analysis revealed that several modifiable pre-operative risk factors remain significant predictors of medium term mortality, including Diabetes(Hazard Ratio(HR) 1.73, 95\%Cl I.2I-2.45), Chromic obstructive pulmonary disease( $(\mathrm{HR} \quad 2.02,95 \% \mathrm{Cl} \quad 1.09-3.72)$, Peripheral vascular disease $(\mathrm{HR} \quad 1.68,95 \% \mathrm{Cl}$ I.13-2.5), Body mass index $>30(\mathrm{HR} \quad 1.54,95 \% \mathrm{Cl} \quad 1.08-2.20)$ and current smoker at operation(HR I.67, $95 \% \mathrm{Cl}$ 1.03-2.72). However hypertension(HR I.3I, $95 \% \mathrm{Cl} \quad 0.95-1.82$ ) and Hypercholestrolaemia(HR $0.8 \mathrm{I}, 95 \% \mathrm{Cl} 0.58-\mathrm{I} .13$ ) were not predictive which may reflect adequate post-operative control.

Conclusion: Coronary artery bypass surgery using cross clamp fibrillation is associated with a very low operative mortality. Medium term survival is also good but risk factors such as smoking at operation, Chronic obstructive pulmonary disease, obesity and diabetes negatively impact this survival and should be aggressively treated in the years post-surgery.
\end{abstract}

\section{Introduction}

The ultimate aim of coronary artery bypass grafting is to achieve long term patency of coronary bypass grafts and therefore long term symptom free survival. Therefore every technique of bypass grafting should be judged by these outcome measures. Many studies have been performed to assess the long term survival in patients undergoing coronary surgery using cardioplegic on-pump surgery[1-4] and also off-pump bypass grafting [5-7]. Indeed a recent statement from the American Heart Asso- 
ciation compared the long term outcomes between the two techniques[8]. However there have been no studies reporting the long-term survival of patients undergoing coronary arterial bypass grafting using cross clamp fibrillation. Benefits of this technique include very short crossclamp and bypass times, whilst consistently achieving complete revascularisation. This technique is used by $15 \%$ of UK surgeons [9-11]which equates to around 3500 operations in the UK per year. Thus we sought to assess the medium to long term survival of patients undergoing bypass grafting using cross-clamp fibrillation. Our second aim was to identify risk factors for long term mortality for these patients. Our hypothesis was that we may be able to identify risk factors pre-operatively that may be amenable to modification in the years post surgery, thereby further improving long term survival.

\section{Methods \\ Surgical techniques}

This has been previously described[11]. The heart is approached through a median sternotomy and the left Internal Mammary Artery harvested on a broad pedicle. Papaverine is topically applied. The saphenous vein is routinely used for subsequent grafts unless they are not suitable for harvesting in which case a radial artery or second mammary artery would be used. The patient is placed on cardiopulmonary bypass and the aorta cross-clamped while each distal anastomosis is fashioned. The cross clamp is then removed while the proximal anastomosis is formed. Bypass is performed at 32 degrees centigrade, and pulmonary artery venting is not routinely used.

\section{Data Management}

Local Ethics Board Approval was obtained to utilise our own database for this study and also to obtain survival statistics for each of the patients on our database. All data was prospectively collected on the departmental Patient Access and Tracking System (PATS) (Dendrite). Survival data is available for all residents of England through the National Health Service Strategic Tracing Service, using the patients NHS number as a unique identifier. This was accessed using an Internet based, password secured approach.

Urgent patients were defined as any patient requiring their operation prior to hospital discharge. This included a small number of patients having their operation within 24 hours or referral. A good left ventricular ejection fraction (EF) was defined as an ejection fraction over $50 \%$, moderate $\mathrm{EF} 30-50 \%$ and poor $\mathrm{EF}>30 \%$.

\section{Statistics}

Statistical analysis was performed on SPSS 13.0. Binomial categorical data was compared using the Fisher's test, and the remaining categorical variables were analysed using the Chi-Squared test. Continuous data was analysed using the unpaired T-test if normality could be established, and skewed or rank data was analysed using the Mann Whitney U test. Multivariate analysis was performed using Cox regression and all variables that demonstrated a univariate significant predictive ability for mortality to a p-value $<0.2$ were entered into the model. Of note parsonnet score was not entered into the multivariate analysis as it is a composite score of multiple potential univariate predictors, and may thus mask their predictive ability.

\section{Results}

From Feb 1996 to through to Jan 2003, a total of 1177 patients were identified as having either elective or urgent first time isolated CABG. $80 \%(939 / 1177)$ of patients were male and mean age was 63 years (Standard Deviation(SD) 9.7 years). $73 \%$ had triple vessel disease, $22 \%$ had double vessel disease and $5 \%$ had single vessel disease. $17 \%$ had left main stem disease. Mean number of grafts was 3.24 (Range 1-6). Mean follow up was 5.3 years (range 0-9.4 years, minimum follow up of living patients was 892 days). The full demographics for this study are shown in table 1 together with their ability to predict medium term mortality.

Average cross clamp time was 27 minutes (SD 11.7) and mean bypass time was 67 minutes (SD 25). The short term complication rate was low (Table 2). The IABP usage was $1.4 \%$ (17/1177 patients), Inotropes were used in $14 \%$ (167/1177 patients). The re-operation rate was $3.5 \%$ (35/ 1177 patients) and the rate of sternal re-wiring was $0.7 \%$ (8/1177 patients). The readmission to ICU rate was $2 \%$ (23/1177 patients). The 30 day mortality was $1.6 \%$ (19 patients).

Mean follow up was 5.3 years and the 5-year survival was $86 \%$. Follow up was performed up to 9 years and the survival at this stage was $79 \%$ across the whole group. This survival was significantly dependant on both age and parsonnet score as might be expected (Figures 1 and 2). Survival at 8 years for the various age categories were: under 55 years: $91 \%$, 55-65 years: $83 \%, 65-75$ years: $74 \%$, over 75 years: $45 \%$.

Our survival compared well with the UK survival rates of healthy residents of our region supplied by the Office of National Statistics. For example the 9 years survival of a healthy 63 year old in our region was $83 \%$, and in our study our 9 year survival was $79 \%$ (Our mean age is 63 in our database)

We analysed the database for significant medium term predictors of mortality (Table 3 ). We found that several modifiable pre-operative risk factors persisted as postoperative risk factors. The presence of any type of diabetes 
Table I: Study Demographics

\begin{tabular}{|c|c|c|c|c|}
\hline & Total $(\mathrm{N}=1177)$ & Survivors $(N=1018)$ & Non-long term Survivor $(\mathrm{N}=159)$ & P-value \\
\hline Male (\%) & $939(80 \%)$ & $823(81 \%)$ & 116 (73\%) & $P=0.026$ \\
\hline female $(\%)$ & $238(20 \%)$ & $195(19 \%)$ & $43(27 \%)$ & \\
\hline Age Mean (SD) & 63 years $(9.7)$ & $62(9.6)$ & $68(9.8)$ & $P<0.0001$ \\
\hline CCSI & $124(10 \%)$ & 107 (11\%) & 17 (1 I\%) & $P=0.01$ \\
\hline II & $335(29 \%)$ & $307(30 \%)$ & $28(18 \%)$ & \\
\hline III & $429(36 \%)$ & $373(36 \%)$ & $56(35 \%)$ & \\
\hline IV & $289(25 \%)$ & $231(23 \%)$ & $58(36 \%)$ & \\
\hline Previous MI & $552(47 \%)$ & $457(45 \%)$ & $95(60 \%)$ & $P=0.01$ \\
\hline Prev Cardiological Intervention & $87(7.4 \%)$ & $78(7.7 \%)$ & $9(5.7 \%)$ & $P=0.42$ \\
\hline Diabetes & $203(17 \%)$ & $162(16 \%)$ & $41(26 \%)$ & $P=0.003$ \\
\hline Hypertension & $573(49 \%)$ & $487(48 \%)$ & $86(54 \%)$ & $P=0.012$ \\
\hline Hypercholestrolemia & $843(71 \%)$ & 749 (74\%) & $94(59 \%)$ & $P<0.0005$ \\
\hline Current smoker & $73(6.2 \%)$ & $62(6.1 \%)$ & II (6.9\%) & $P=0.723$ \\
\hline COPD & $36(3.1 \%)$ & $23(2.3 \%)$ & $13(8.2 \%)$ & $P<0.0005$ \\
\hline PVD & 146 (I2\%) & $110(11 \%)$ & $36(23 \%)$ & $P<0.0005$ \\
\hline \multicolumn{5}{|l|}{ Coronary Disease } \\
\hline Single & $56(4.8 \%)$ & $54(5.3 \%)$ & $2(1.3 \%)$ & $P=0.860$ \\
\hline Double & $258(22 \%)$ & $234(23 \%)$ & $24(15 \%)$ & \\
\hline Triple & 863 (73\%) & $730(72 \%)$ & 133 (84\%) & \\
\hline LMS disease & $202(17 \%)$ & $173(17 \%)$ & $29(18 \%)$ & $P=0.734$ \\
\hline EF Good & 777 (66\%) & $701(69 \%)$ & $76(48 \%)$ & $P<0.0005$ \\
\hline Fair & $308(26 \%)$ & $253(25 \%)$ & $55(34 \%)$ & \\
\hline Poor & $92(8 \%)$ & $64(6 \%)$ & $28(18 \%)$ & \\
\hline Pre-op IABP & $17(1.4 \%)$ & II (I.I\%) & $6(3.8 \%)$ & $P=0.019$ \\
\hline No of distal anastomoses & 3.24 (0.97) Range I-6 & $3.24(0.98)$ & $3.26(0.91)$ & $P=0.844$ \\
\hline Bypass time & 67 mins $(25)$ & 66 mins $(24)$ & 75 mins (32) & $P=0.002$ \\
\hline X-Clamp time & 27 mins (II) & 27 mins (12) & 27 mins (10) & $P=0.769$ \\
\hline $\mathrm{BMI}>30$ & 307 (28\%) & $259(27 \%)$ & $48(31 \%)$ & $P=0.190$ \\
\hline Trasylol & $243(21 \%)$ & $210(21 \%$ & $33(21 \%)$ & $P=1.000$ \\
\hline
\end{tabular}

significantly predicted adverse medium term mortality (Odds ratio(OR) 1.73, 95\%CI 1.21-2.45). Also presence of chronic obstructive pulmonary disease predicted medium term mortality (Hazard Ratio(HR) 2.02, 95\%CI 1.09-3.72), peripheral vascular disease predicted medium term mortality (HR 1.68, 95\%CI 1.13-2.5) and a Body Mass Index(BMI) of over 30 predicted mortality(HR 1.54, 95\%CI 1.08-2.20). Current smoker at operation (HR 1.67, 95\%CI 1.03-2.72) also predicted medium term mortality. However hypertension (HR 1.31, 95\%CI $0.95-1.82$ ) and Hypercholestrolaemia (HR 0.81, 95\%CI $0.58-1.13$ ) failed to reach significance.

\section{Comment}

We have demonstrated that coronary arterial bypass grafting using cross-clamp fibrillation is associated with low short and medium term mortality. Furthermore we have demonstrated that in the years post-cardiac surgery, mod-

Table 2: Post operative complications

\begin{tabular}{|c|c|c|c|c|}
\hline & Total $(\mathrm{N}=1177)$ & Survivors $(N=1018)$ & Non-long term Survivor $(N=159)$ & P-value \\
\hline IABP & 14 (I.2\%) & $8(0.8 \%)$ & $6(3.8 \%)$ & $P=0.001$ \\
\hline Inotropes & $167(14 \%)$ & $138(14 \%)$ & $29(18 \%)$ & $P=0.001$ \\
\hline Atrial Fibrillation & $236(20 \%)$ & $202(20 \%)$ & $34(21 \%)$ & $P=0.670$ \\
\hline Blood given post-op & $217(19 \%)$ & $164(16 \%)$ & $53(34 \%)$ & $P<0.0005$ \\
\hline Blood loss post-op (SD) & $821 \mathrm{mls}(566)$ & $820 \mathrm{mls}(552)$ & $831 \mathrm{mls}(650)$ & $P=0.829$ \\
\hline Re-operation & $35(3 \%)$ & $23(2.3 \%)$ & $12(7.5 \%)$ & $P=0.001$ \\
\hline Sternal resuturing & $8(0.7 \%)$ & $2(0.2 \%)$ & $6(3.8 \%)$ & $P<0.0005$ \\
\hline Parsonnet (SD) & $6.2(6.2)$ & $5.7(5.9)$ & $9.8(7.0)$ & $P<0.0005$ \\
\hline Renal Failure & $51(4.3 \%)$ & $28(2.8 \%)$ & $23(15 \%)$ & $P<0.0005$ \\
\hline Reintubation & II (0.9\%) & $6(0.6 \%)$ & $5(3.1 \%)$ & $P=0.010$ \\
\hline ICU readmission & $23(2 \%)$ & $\mathrm{II}(\mathrm{I} .1 \%)$ & $12(7.5 \%)$ & $P<0.0005$ \\
\hline
\end{tabular}


Sunvival by Parsonnet score

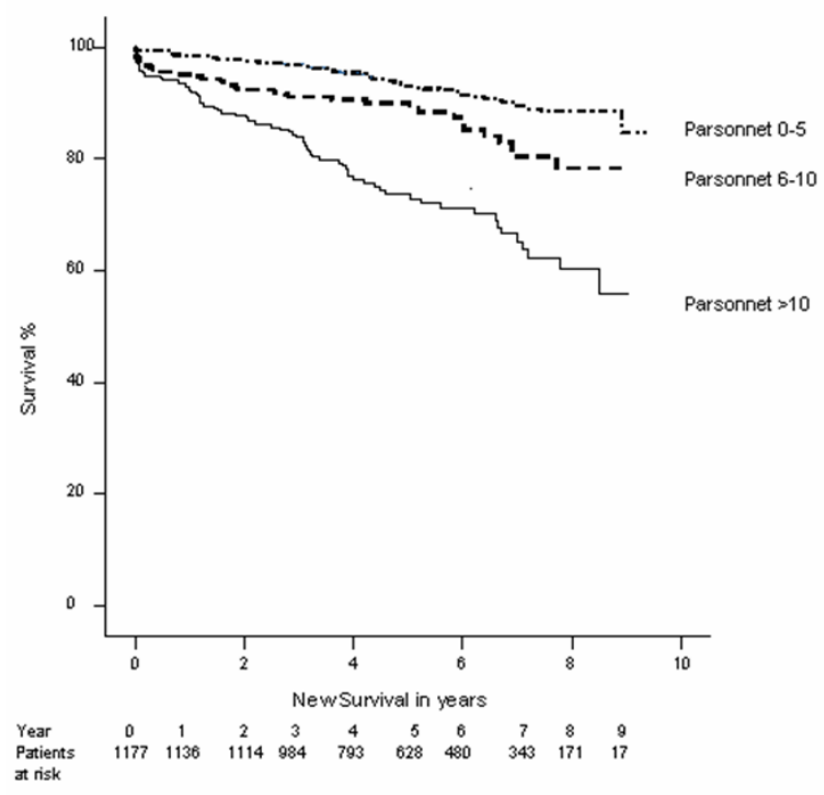

Figure I

Kaplain-Meier Survival plot by Parsonnet score.

ifiable risk factors remain a significant cause of mortality. Hypertension and high cholesterol did not show a significant association in our database. This may be due to the fact that these risk factors are now aggressively treated by cardiologists and general practitioners in the years post cardiac surgery. In the United Kingdom and internationally, guidelines exist for the control of both hypertension and cholesterol in the community and are regarded as being well adhered to[12,13].

In contrast diabetes, peripheral vascular disease, a high BMI, and current smoking all adversely affected long term mortality. We hypothesise that these risk factors are not as successfully treated in the years after cardiac surgery. It is our experience that patients who smoke through their admission for cardiac surgery invariably fail to stop smoking in the immediate post operative period. In addition patients with a high BMI also tend to fail to lose weight post operatively. Peripheral vascular disease may reflect patients with an aggressive atherosclerotic process in several other organs in addition to the heart and thus the risk of mortality due to other causes may be higher.

We have shown that diabetes remains a risk factor for late mortality. Further studies would be required to determine whether tighter glucose control would improve survival or whether this effect reflects the poorer prognosis of patients with diabetes although the association with

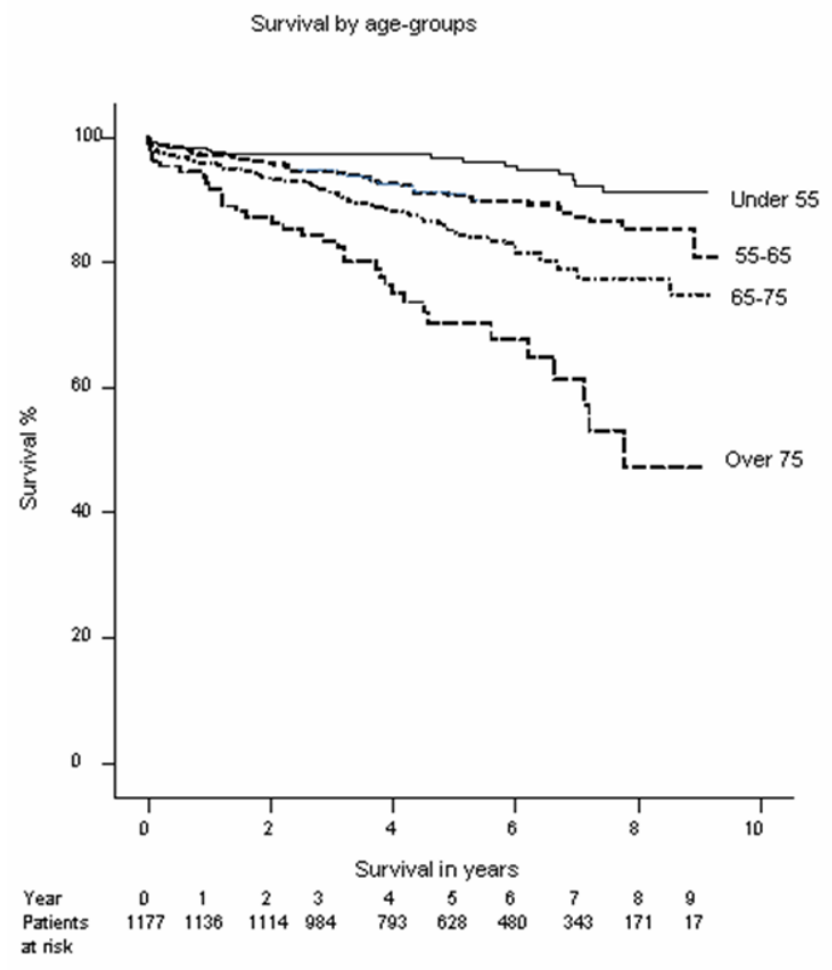

Figure 2

Kaplain-Meier survival plot by agegroup.

tighter glucose control and survival is well established[14].

Gardner et al[15] performed a retrospective analysis of 11,815 patients undergoing coronary surgery in 43 US hospitals, searching for risk factors for 6 month survival. Their survival at 6 months was $93.8 \%$ and they found that

Table 3: Predictors of medium term mortality as determined by Cox Regression analysis

\begin{tabular}{lcccc}
\hline & $\begin{array}{c}\text { Hazard } \\
\text { ratio }\end{array}$ & $\begin{array}{c}95.0 \% \text { Cl for Odds } \\
\text { ratio }\end{array}$ & Sig. \\
& & Lower & Upper & \\
\hline Diabetes & 1.735 & 1.208 & 2.492 & 0.003 \\
hypercholestrolaemia & 0.808 & 0.575 & 1.133 & 0.217 \\
Hypertension & 1.317 & 0.953 & 1.821 & 0.096 \\
Pre-op renal failure & 5.125 & 2.512 & 10.458 & $<0.0005$ \\
COPD & 2.017 & 1.094 & 3.718 & 0.025 \\
Peripheral Vascular disease & 1.677 & 1.127 & 2.495 & 0.011 \\
EF 30-50\% & 1.483 & 1.026 & 2.143 & 0.036 \\
EF <30\% & 2.141 & 1.316 & 3.483 & 0.002 \\
BMI >30 & 1.540 & 1.079 & 2.198 & 0.017 \\
Current smoker at & 1.673 & 1.031 & 2.715 & 0.037 \\
Operation & & & & \\
Age at operation & 1.072 & 1.050 & 1.094 & $<0.0005$ \\
\hline
\end{tabular}


Chronic Obstructive Pulmonary disease (COPD), cerebrovascular disease and older age predicted 6 month mortality.

Boucher et al [16] studied 329 patients over 70 years of age after cardiac surgery. They reported a $9.4 \%$ operative mortality and thereafter a 5 -year survival of $86 \%$ which was comparable with the background population in their area. Their survival was comparable to that in our own study.

Caputo et al [17] reported the medium term survival of 1,479 patients who had undergone off-pump coronary arterial revascularisation. They reported a 2 year mortality of $4.7 \%$ in patients who received a complete revascularisation. Of note they found a $10.8 \% 2$ year mortality in patients who received an incomplete revascularisation. Our 2 year survival is therefore comparable to this cohort of patients operated on with off pump surgery with complete revascularization.

The Multicenter Study of Perioperative Ischemia Research Group[18] found in an analysis of 2,048 patients from 24 centres that the 5 year survival was adversely impacted by age, diabetes, congestive heart failure and anaemia, in agreement with our own results.

Gao et al [4] analysed 56,543 patients who underwent CABG at one of 43 veterans hospitals for risk factors for long term survival. They found that diabetes had an increasing impact on survival, eventually doubling mortality at 9 years post-operatively. They also found that COPD, age and urgent surgery persisted as a risk factor in the years post surgery in agreement with our results. Their 5 year survival was $81 \%$ in their cohort of patients with the same mean age as our own.

The CASS registry followed up their cohort of 24,959 patients who underwent coronary artery bypass grafting between 1974 and 1979[2]. Their 10-year survival was $74 \%$ in this cohort of patients who had a mean age of under 55. They identified that risk factors for long term survival included heavier weight, diuretic use, diabetes and smoking. They did not investigate peripheral vascular disease as a risk factor.

Our study has weaknesses. It is retrospective in nature although our follow up is complete due to the fact that the NHS tracing service contains a complete database of all deaths in the UK. We have not yet been able to obtain data on the cause of death for our post-operative patients. In addition we have no information as to the incidence of MI, stroke or reintervention in the years post surgery. This data could potentially provide valuable additional evidence in support of the fact that modifiable risk factors may account for a large proportion of the deaths. This series is a single surgeon's series, and although this eliminates a large amount of perioperative technical heterogeneity associated with other studies, the presence of modifiable risk factors in other surgeons practice would require confirmation. Also we have not provided a detailed account of radial artery or RIMA usage although in our experience this usage was very low in this database. It is possible that long term outcomes may have been superior with arterial conduit usage although the RAPCO randomised study of saphenous vein versus arterial conduits has so far shown no benefit at 5 years after randomization [19]

We conclude that the treatment of coronary atherosclerotic disease by cardiothoracic surgeons should not end on successful discharge from the unit. The cardiothoracic surgeons should ensure that the patient is placed into programmes of smoking cessation, weight loss and diabetes supervision as appropriate. Cardiac Surgeons should ensure that these programmes are effective in their area and ensure that regular audits of their efficacy are conducted.

We have furthermore demonstrated that coronary arterial bypass grafting using cross clamp fibrillation is associated with an equivalent short and medium term survival to patients undergoing coronary revascularization either using cardioplegia or off-pump techniques.

\section{Abbreviations}

BMI Body mass index

CABG Coronary artery bypass grafting

CI Confidence Interval

COPD Chronic Obstructive Pulmonary Disease

EF Ejection Fraction

HR Hazard ratio

IABP Intra-aortic Balloon Pump

ICU Intensive Care Unit

LMS left main stem

MI Myocardial Infarction

NHS National Health Service

OR Odds ratio 
PATS Patient Access and Tracking System

PVD Peripheral Vascular disease

SD Standard Deviation

SPSS Statistical Package for Social Sciences

UK United Kingdom

\section{Acknowledgements}

I would like to acknowledge the considerable assistance from my secretary Mrs D Teh.

\section{References}

I. Goldman S, Zadina K, Moritz T, Ovitt T, Sethi G, Copeland JG, Thottapurathu L, Krasnicka B, Ellis N, Anderson RJ, Henderson W, Group VACS: Long-term patency of saphenous vein and left internal mammary artery grafts after coronary artery bypass surgery: results from a Department of Veterans Affairs Cooperative Study. In J Am Coll Cardiol Volume 44. United States; 2004:2149-2I 56.

2. Myers WO, Blackstone EH, Davis K, Foster ED, Kaiser GC, Myers WO, Blackstone EH, Davis K, Foster ED, Kaiser GC: CASS Registry long term surgical survival. Coronary Artery Surgery Study. In J Am Coll Cardiol Volume 33. UNITED STATES; 1999:488-498.

3. Gao G, Wu Y, Grunkemeier GL, Furnary AP, Starr A: Long-term survival of patients after coronary artery bypass graft surgery: comparison of the pre-stent and post-stent eras. [see comment]. In Ann Thorac Surg Volume 82. Netherlands; 2006:806-8I0.

4. Gao D, Grunwald GK, Rumsfeld JS, Schooley L, Mackenzie T, Shroyer AL: Time-varying risk factors for long-term mortality after coronary artery bypass graft surgery. In Ann Thorac Surg Volume 8I. Netherlands; 2006:793-799.

5. Hannan EL, Racz MJ, Walford G, Ryan TJ, Isom OW, Bennett E, Jones $\mathrm{RH}$ : Predictors of readmission for complications of coronary artery bypass graft surgery. In JAMA Volume 290. United States; 2003:773-780.

6. El-Hamamsy I, Cartier R, Demers P, Bouchard D, Pellerin M: Longterm results after systematic off-pump coronary artery bypass graft surgery in 1000 consecutive patients. Circulation 2006, I 1 4:1486-1491.

7. Williams ML, Muhlbaier LH, Schroder JN, Hata JA, Peterson ED, Smith PK, Landolfo KP, Messier RH, Davis RD, Milano CA: Riskadjusted short- and long-term outcomes for on-pump versus off-pump coronary artery bypass surgery. Circulation 2005, I I 2:1366-1370.

8. Sellke FW, DiMaio JM, Caplan LR, Ferguson TB, Gardner TJ, Hiratzka LF, Isselbacher EM, Lytle BW, Mack MJ, Murkin JM, Robbins RC, Association. $\mathrm{AH}$ : Comparing on-pump and off-pump coronary artery bypass grafting: numerous studies but few conclusions: a scientific statement from the American Heart Association council on cardiovascular surgery and anesthesia in collaboration with the interdisciplinary working group on quality of care and outcomes research. In Circulation Volume I II. United States; 2005:2858-2864.

9. Karthik S, Grayson AD, Oo AY, Fabri BM: A survey of current myocardial protection practices during coronary artery bypass grafting. Ann R Coll Surg Engl 2004, 86:4I3-4I5.

10. Bonchek LI, Burlingame MW, Vazales BE, Lundy EF, Gassmann CJ: Applicability of noncardioplegic coronary bypass to high-risk patients. J Thorac Cardiovasc Surg 1992, 1 03:230-237.

I I. Raco L, Mills E, Millner RJ: Isolated myocardial revascularization with intermittent aortic cross-clamping: experience with 800 cases. Annals of Thoracic Surgery 2002, 73:1436-1439.

I2. NICE guidelines: CGI 8 Hypertension( Persistently high blood pressure) in adults. 2004 [http://www.nice.org.uk].

13. Expert Panel on Detection E and Treatment of High Blood Cholesterol in Adults.: Executive Summary of the third report of the
National Cholesterol Education Program (NCEP) expert panel on detection, evaluation, and treatment of high blood cholesterol in adults (Adult Treatment Panel III). Journal of the American Heart Association 200I, 285:2486-2497.

14. The Diabetes Control and Complications Trial/Epidemiology of Diabetes Interventions and Complications (DCCT/EDIC) Study Research Group: Intensive Diabetes Treatment and Cardiovascular Disease in Patients with Type I Diabetes. N Engl J Med 2005, 353:2643-2653.

15. Gardner SC, Grunwald GK, Rumsfeld JS, Mackenzie T, Gao D, Perlin JB, McDonald G, Shroyer AL: Risk factors for intermediate-term survival after coronary artery bypass grafting. Annals of Thoracic Surgery 2001, 72:2033-2037.

16. Boucher JM, Dupras A, Jutras N, Page V, LeLorier J, Gagnon RM: Long-term survival and functional status in the elderly after cardiac surgery. Canadian Journal of Cardiology 1997, 13:646-652.

17. Caputo M, Reeves BC, Rajkaruna C, Awair H, Angelini GD: Incomplete revascularization during OPCAB surgery is associated with reduced mid-term event-free survival. Annals of Thoracic Surgery 2005, 80:2|4|-2|47.

18. Koch CG, Weng YS, Zhou SX, Savino JS, Mathew JP, Hsu PH, Saidman LJ, Mangano DT, Foundation IRE, Multicenter Study of Perioperative Ischemia Research Group: Prevalence of risk factors, and not gender per se, determines short- and long-term survival after coronary artery bypass surgery. [Review] [4I refs]. Journal of Cardiothoracic \& Vascular Anesthesia I 7(5):585-93, 2003.

19. Hayward PA, Buxton BF: Contemporary coronary graft patency: 5-year observational data from a randomized trial of conduits. Ann Thorac Surg 2007, 84:795-799.
Publish with Bio Med Central and every scientist can read your work free of charge

"BioMed Central will be the most significant development for disseminating the results of biomedical research in our lifetime. "

Sir Paul Nurse, Cancer Research UK

Your research papers will be:

- available free of charge to the entire biomedical community

- peer reviewed and published immediately upon acceptance

- cited in PubMed and archived on PubMed Central

- yours - you keep the copyright

Submit your manuscript here:

http://www.biomedcentral.com/info/publishing_adv.asp
BioMedcentral 